\title{
Lipid and fatty acid metabolism in trypanosomatids
}

\author{
Giovana Parreira de Aquino, ${ }^{1, \#, ~ M a r c o ~ A n t o n i o ~ M e n d e s ~ G o m e s ~}{ }^{1, \#}$, Roberto Köpke Salinas² and \\ Maria Fernanda Laranjeira-Silva ${ }^{1, *}$ \\ ${ }^{1}$ Department of Physiology, Institute of Biosciences, University of São Paulo, São Paulo, Brazil. \\ 2 Department of Biochemistry, Institute of Chemistry, University of São Paulo, São Paulo, Brazil. \\ \# These authors contributed equally to this work. \\ * Corresponding Author: \\ Maria Fernanda Laranjeira-Silva, Department of Physiology, Institute of Biosciences, University of São Paulo, São Paulo, Brazil; \\ E-mail:mfernandals@usp.br
}

\begin{abstract}
Trypanosomiases and leishmaniases are neglected tropical diseases that have been spreading to previously nonaffected areas in recent years. Identification of new chemotherapeutics is needed as there are no vaccines and the currently available treatment options are highly toxic and often ineffective. The causative agents for these diseases are the protozoan parasites of the Trypanosomatidae family, and they alternate between invertebrate and vertebrate hosts during their life cycles. Hence, these parasites must be able to adapt to different environments and compete with their hosts for several essential compounds, such as amino acids, vitamins, ions, carbohydrates, and lipids. Among these nutrients, lipids and fatty acids (FAs) are essential for parasite survival. Trypanosomatids require massive amounts of FAs, and they can either synthesize FAs de novo or scavenge them from the host. Moreover, FAs are the major energy source during specific life cycle stages of $T$. brucei, $T$. cruzi, and Leishmania. Therefore, considering the distinctive features of FAs metabolism in trypanosomatids, these pathways could be exploited for the development of novel antiparasitic drugs. In this review, we highlight specific aspects of lipid and FA metabolism in the protozoan parasites $T$. brucei, $T$. cruzi, and Leishmania spp., as well as the pathways that have been explored for the development of new chemotherapies.
\end{abstract}

doi: $10.15698 /$ mic2021.11.764

Received originally: 17.05.2021;

in revised form: 03.09.2021,

Accepted 13.09.2021,

Published 06.10.2021.

Keywords: Trypanosoma brucei, Trypanosoma cruzi, Leishmania, neglected tropical diseases, host-parasite interaction, chemotherapeutics, elongases.

\begin{abstract}
Abbreviations:
$\boldsymbol{A A}$ - arachidonic acid; $\boldsymbol{A C C}$ - acetyl-CoA-carboxylase; AmB - amphotericin B; AST - aspartate aminotransferase; BSF - bloodstream form; CFA cyclopropane FA; CFAS - CFA synthase; DAG diacylglycerol; EPC - ethanolamine phosphorylceramide; ELO - elongase; ER endoplasmic reticulum; FA - fatty acid; FABP - fatty acid binding protein; FAS - FA synthesis; GPI glycosylphosphatidylinositol; HAT - human African trypanosomiasis; IPC - inositol phosphorylceramide; LD - lipid droplet; $\mathbf{L D K}$ - LD kinase; PC phosphatidylcholine; PCF - procyclic form; PE phosphatidylethanolamine; PL - phospholipid; $\boldsymbol{S b}^{\mathbf{v}}$ pentavalent antimonials; SL - sphingolipid; VSG variant surface glycoprotein.
\end{abstract}

\section{INTRODUCTION}

Trypanosomiases and leishmaniases are vector-borne diseases caused by protozoan parasites of the Trypanosomatidae family. Both are considered neglected tropical diseases as they prevail in tropical and subtropical developing countries, particularly affecting those living in poverty. In addition, currently available treatments are often toxic and ineffective. There are no available vaccines, therefore, effective control can only be achieved by population-based public health interventions [1].

Human African trypanosomiasis (HAT, also known as sleeping sickness) is caused by the hemoflagellate Trypanosoma brucei. HAT is endemic in sub-Saharan Africa, af- fecting mainly rural areas [2]. The disease is transmitted by the injection of metacyclic trypomastigotes into the mammalian host skin through the bite of an infected tsetse fly [2]. The parasites proliferate and later establish bloodstream infection [3]. The bloodstream forms (BSFs) are found in the blood, lymph, and cerebrospinal fluid. American trypanosomiasis, also known as Chagas disease, is caused by Trypanosoma cruzi, and is transmitted to humans by contact with feces and/or urine of infected bloodsucking triatomine insects. In the mammalian host, the infective metacyclic trypomastigote forms penetrate the dermis, reach the blood, and infect all types of nucleated cells, where they differentiate into intracellular amastigote 
forms [4]. Chagas disease is endemic in South and Central Americas but due to environmental changes and migration, it has been spreading to previously non-affected areas including countries in Europe [5], North America [6], Africa, and Western Pacific regions [7]. This disease can also be transmitted through oral non-vectorial routes by ingestion of contaminated food, such as açai pulp products $[8,9]$ and sugarcane juice [8]. Leishmaniases are caused by at least 22 species of the genus Leishmania [10]. The infective metacyclic forms of these parasites are transmitted by hematophagous phlebotomine sandflies during a blood meal. Inside the vertebrate host, Leishmania parasites infect phagocytes such as neutrophils and macrophages, where they differentiate into intracellular amastigote forms [10]. These diseases are endemic in 98 countries worldwide, affecting mainly poor regions of South America, Africa, and South-East Asia [11]. Leishmaniases have also been spreading to other regions due to environmental changes, migration, and socioeconomic factors [1, 12].

During their life cycle, trypanosomatid parasites undergo significant environmental changes in temperature, $\mathrm{pH}$, and nutrients availability as they alternate between invertebrate and vertebrate hosts $[13,14]$. To survive and thrive, they must adapt to these different environments and compete with their hosts for several essential compounds including amino acids, vitamins, ions, carbohydrates, and lipids [13, 15-18]. Among these nutrients, lipids and fatty acids (FAs) are essential for parasite growth and survival $[19,20]$.

Trypanosomatids can either synthesize FAs de novo or scavenge them from the host. These parasites require substantial amounts of FAs to build the lipid anchors of the glycosylated proteins that decorate the parasite cell surface [21]. For instance, myristate is synthesized intracellularly and esterified to glycosylphosphatidylinositol (GPI) [21], which is a molecule that anchors surface proteins like the variant surface glycoproteins (VSGs), essential for immune system evasion by T. brucei BSFs [21]. In addition, disruption of mitochondrial FAs synthesis affects the morphology and function of T. brucei mitochondria [20]. It was also observed that lipid extracts of Leishmania infantum may induce macrophage polarization into the M2 phenotype [22], promoting pathogen replication rather than elimination [23]. Besides, during specific life cycle stages of T. brucei, T. cruzi, and Leishmania, FAs are oxidized and become the major energy source [24-26]. Noteworthily, some parasite forms can accumulate in the host adipose tissue $[24,27]$. In this niche, scavenging FAs from adipocytes may be advantageous to fulfill the parasite nutritional needs, as observed in T. brucei [24].

\section{LIPID AND FATTY ACID ACQUISITION AND STORAGE}

The endocytic process is a well-established pathway of FA acquisition that occurs almost exclusively in the flagellar pocket of trypanosomatids (reviewed in [28]; Figure 1). As demonstrated by heavy water labeling experiments, Leishmania mexicana amastigotes derived from skin lesions appear to be highly dependent on myristic, palmitic, and palmitoleic acid salvage pathways, although it's not yet clear how these molecules are internalized [29].

T. brucei, T. cruzi, and Leishmania amazonensis must acquire cholesterol from the medium as they are not able to synthesize it. They are capable of internalizing lowdensity lipoprotein (LDL) by receptor-mediated endocytosis [30-33]. T. cruzi and T. brucei can also internalize highdensity lipoprotein (HDL) through receptor-mediated endocytosis (Figure 1B, 1C) [34-37]. Despite being able to synthesize ergosterol, it was shown that $T$. brucei BSFs meet their sterol requirement via host cholesterol uptake, while procyclic forms (PCFs) rely mainly on de novo ergosterol biosynthesis. Importantly, cholesterol uptake seems to suppress C28-sterol synthesis in T. brucei BSFs [38]. In addition, $T$. brucei BSFs present an extra three-step pathway to acquire lysophospholipids (LPCS) from the host: hydrolysis mediated by phospholipase A1 (PLA1), esterification with coenzyme $A$, and acylation mediated by an acyltransferase (AT; Figure 1B). The first step of this pathway releases free FAs in the cytoplasm that can also be used in other pathways [39].

Although FA uptake was detected in these parasites, the mechanisms of FA incorporation are not fully understood. Bioinformatic studies indicate the presence of Fatty Acid Binding Protein (FABP)-like proteins in trypanosomatids with a potential role in uptake and transport of FA [37]. These studies showed the T. brucei mitochondrial aspartate aminotransferase (AST) presents high amino acid sequence identity to the mammalian plasma membrane FABP (FABPpm), suggesting that $T$. brucei may use this FABPpm-like AST in a similar manner to scavenge FA from the host. Moreover, since FAs concentration in plasma is low, bovine serum albumin (BSA) endocytosis also represents an important route for FA uptake, as shown with T. cruzi epimastigotes and T. brucei BSFs [28].

Numerous structurally different FABPs have already been identified in other pathogenic organisms such as Echinococcus granulosus [40], Schistosoma mansoni [41], Ascaris suum [42], Mycobacterium tuberculosis [43], Staphylococcus aureus [44, 45], and Streptococcus pneumoniae [46]. In S. aureus and S. pneumoniae, FABPs called FakBs mediate incorporation of exogenous FAs [44]. FakB exchanges its bound acyl-phosphate for a membrane FA. Then the glycerol 3-phosphate acyltransferase (PIsY) utilizes the released acyl-phosphate to produce lysophosphatidic acid, which is required for phospholipid (PL) synthesis [44]. X-ray crystallographic analysis of FakB revealed a twodomain protein fold forming a narrow tunnel that accommodates a FA ligand $[47,48]$. In contrast, the FABPs of the nematode worms $E$. granulosus, S. mansoni, and $A$. suum are structurally similar to mammalian FABPs. In mammalian cells, FABPs are also involved in FA trafficking [49] and display a $\beta$-barrel structure. This structure encloses a solvent accessible cavity that accommodates the ligand, and a helix-turn-helix motif on one side of the $\beta$-barrel covers the cavity [42, 50, 51]. FABP-like proteins displaying the $\beta$-barrel fold were also observed in some Gram-positive bacteria. For instance, $M$. tuberculosis studies identified Rv0813c as a hypothetical protein with high similarity to 


\section{A Leishmania spp}

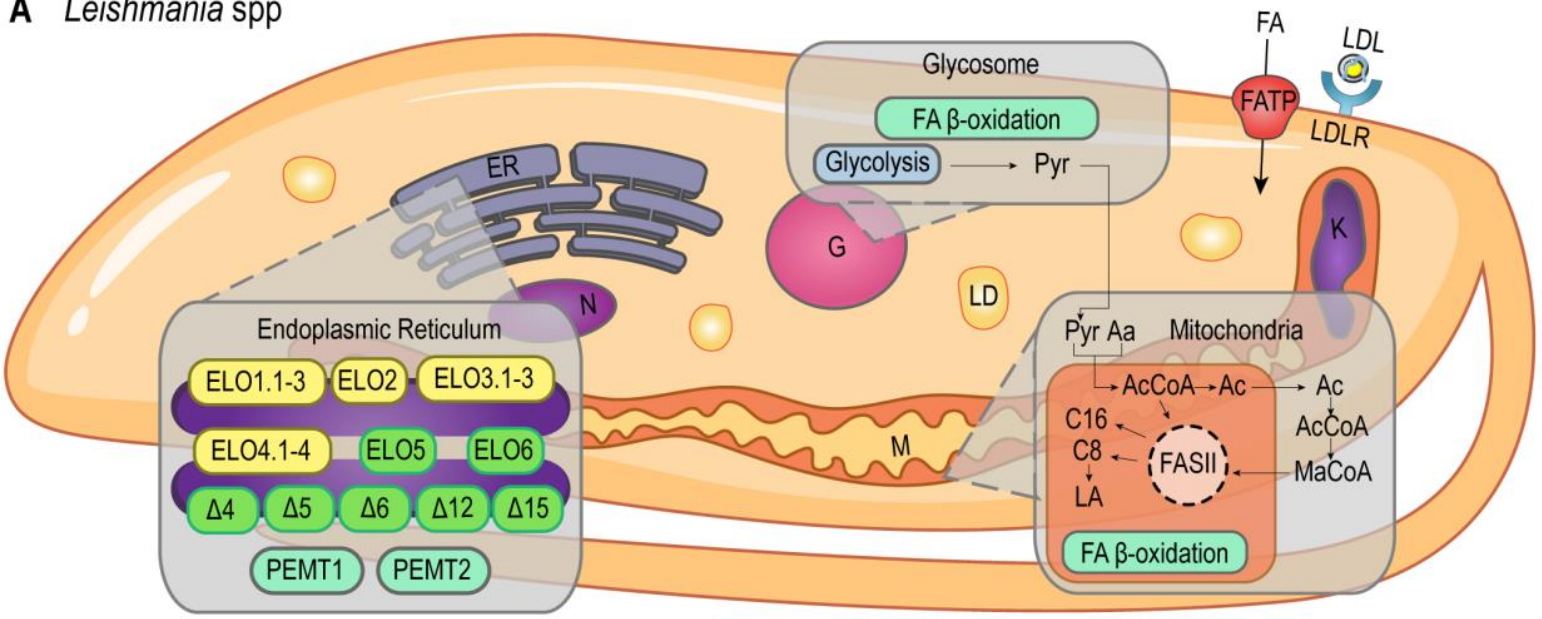

B Trypanosoma brucei

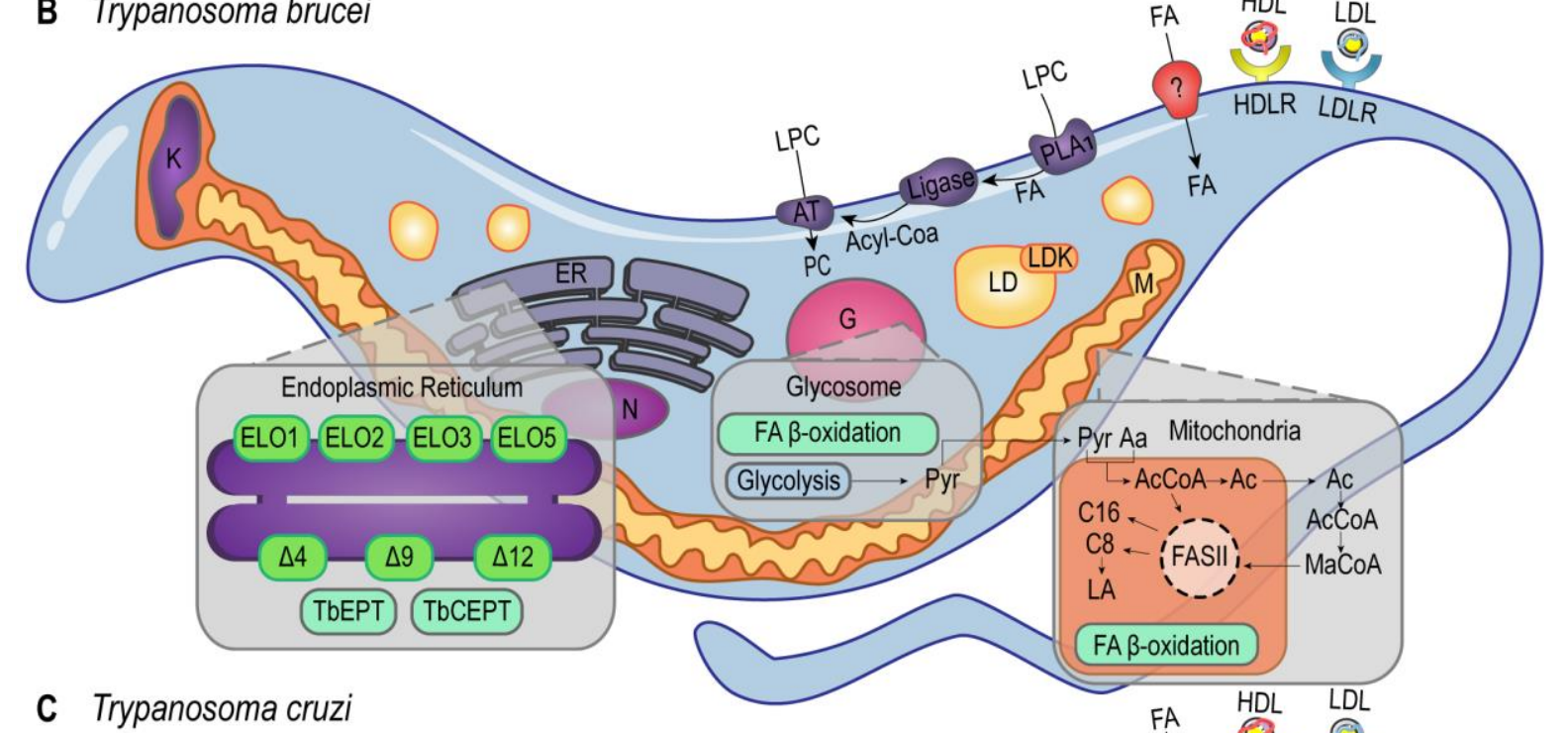

C Trypanosoma cruzi

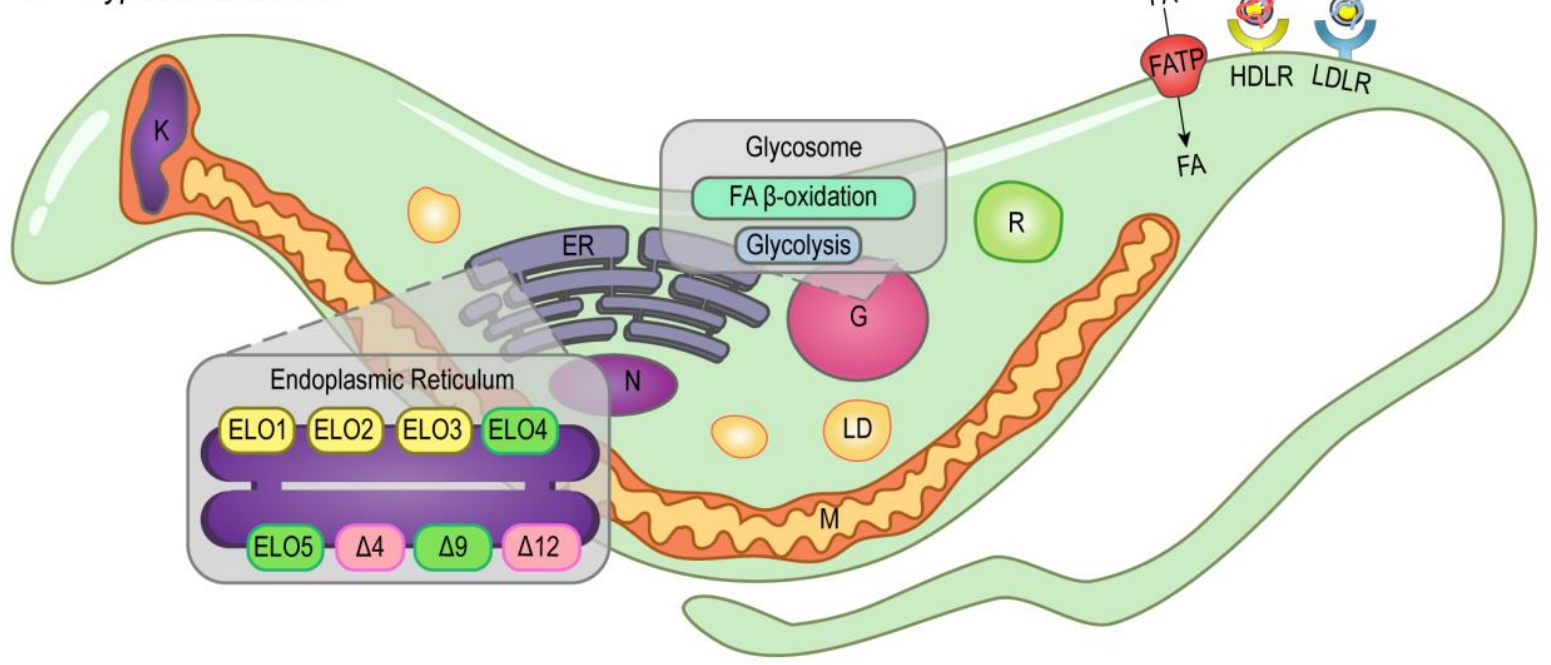

FIGURE 1: Lipid and FA pathways in Leishmania spp., T. brucei and $T$. cruzi. Schematic illustration of lipid and FA acquisition and metabolic pathways identified in Leishmania spp. (A), T. brucei (B) and T. cruzi (C). Aa - Aminoacid; AcCoA - Acetyl CoA; AT - Acetyltransferase; C8 - Octanoic acid; C16 - Palmitic acid; ELO1.1-3, ELO2, ELO3.1-3, ELO4.1-4, ELO5, ELO6 - Elongases; ER - Endoplasmic Reticulum; FA - Fatty Acid; FASII - Fatty Acid Synthase II; FAT - Fatty Acid Transporter; G Glycosome; HDL - High Density Lipoprotein; HDLR - High Density Lipoprotein Receptor; K - Kinetoplast; LA - Lipoic acid; LD - Lipid Droplets; LDK - Lipid Droplet Kinase; LDL - Low Density Lipoprotein; LDLR - Low Density Lipoprotein Receptor; LPC - Lysophosphatidylcholine; M - Mitochondria; MaCoA - Malonyl-CoA; N - Nucleus; PC - Phosphatidylcholine; PEMT1 - Phosphatidylethanolamine Methyltransferase 1; PEMT2 - Phosphatidylethanolamine Methyltransferase 2; PLA1 - Phospholipase 1; Pyr - Pyruvate; R - Reservosomes; TbCEPT - Choline/Ethanolamine Phosphotransferase; TbEPT - Ethanolamine Pphosphotransferase; $\Delta 4-6, \Delta 9, \Delta 12, \Delta 15$ Desaturases. Yellow boxes, Leishmania spp. putative genes (ELO1.1-3, ELO2, ELO3.1-3, ELO4.1-4 in A). Green boxes, characterized proteins (ELO5, ELO6 and desaturases in A; ELO1, ELO2, ELO3, ELO5 and desaturases in B; ELO5 and $\Delta 9$ in C). Pink boxes, protein activity detected in $T$. cruzi ( $\Delta 4$ and $\Delta 12$ in C). 
the $\beta$-barrel FABPs of mammals. Such findings uncovered a new family of bacterial proteins structurally similar to eukaryotic cellular retinol-binding proteins (CRBPs), cellular retinoic acid-binding proteins (CRABPs), and FABPs [43].

Regarding storage, $T$. cruzi epimastigotes accumulate exogenous lipids in round-shaped genus-specific organelles called reservosomes (Figure 1C) [16], the last compartment of the epimastigotes endocytic pathway [28]. The major content of these unique organelles is neutral lipids, mainly cholesterol and cholesteryl esters. It was shown during serum starvation that epimastigotes can mobilize high amounts of lipids from reservosomes to meet cellular demands [16], and the internalized cholesterol is redistributed to the plasma membrane in starved parasites [52]. Furthermore, previous studies have demonstrated that reservosomes undergo a progressive involution during metacyclogenesis, suggesting the storage of lipids in these organelles may be particularly important during parasite differentiation $[16,53]$.

Lipid droplets (LDs), or lipid bodies (LBs), are other lipid-storage compartments found in the cytosol of $T$. brucei [54], Leishmania major intracellular amastigotes [55] and T. cruzi epimastigotes [56] (Figure 1). These organelles are delimited by a PL monolayer [57] and they accumulate exogenous cholesterol in the form of cholesteryl-esters [58]. However, while reservosomes lipid stocks are preferentially consumed over LDs stocks during lipid starvation in T. cruzi epimastigotes [52], LDs could have a role during infection [59]. As demonstrated in transmission electron microscopy (TEM) studies, the production of LDs in the cytoplasm of $T$. cruzi trypomastigotes is a response to host interaction and inflammatory signals. These studies have also shown that exogenous arachidonic acid (AA) stimulates LDs formation that then incorporate AA [60]. Besides, parasite LDs can act as a site for prostaglandin E2 ( $\left.\mathrm{PGE}_{2}\right)$ production, reinforcing LDs role in disease outcome [60]. Similarly, during Leishmania infantum chagasi metacyclogenesis, LDs are intracellular sites of prostaglandin production promoting macrophage infection [61]. It was shown that oleate is incorporated into PLs and triacylglycerols (TAGs) for storage in LDs of $T$. brucei PCFs [62]. RNAi experiments revealed that LDs biogenesis in these parasites relies on a protein kinase, called lipid droplet kinase (LDK) [54], and a lipin-like enzyme that converts phosphatidic acid PLs into diacylglycerol (DAG), called TbLpn, which is essential for PCFs growth [63]. Colocalization assays indicated that LDK is located on the PL monolayer of LDs, whereas TbLpn is distributed throughout the cytosol.

\section{FATTY ACID BIOSYNTHESIS}

Unlike other eukaryotes, trypanosomatids use the elongase (ELO) system to synthesize most of the required FAs $[37,64,65]$. The ELO enzymes are endoplasmic reticulum (ER) integral membrane proteins that catalyze the extension of acyl chains. T. brucei uses a modular system of three ELOs to synthesize FAs from C4 to C18, TbELO1-3 (Figure 1B) [64]. TbELO1 extends C4 to C10, TbELO2 extends $\mathrm{C} 10$ to $\mathrm{C} 14$, and TbELO3 extends C14 to
C18. Noteworthily, the downregulation of TbELO3 in BSFs may cause the accumulation of myristate (C14), an important component of the VSGs GPI-anchors as discussed earlier [21, 64].

$T$. cruzi and $L$. major genomes also have genes encoding putative ELO1-3 proteins (Figure 1A, 1C), although they were shown to encode additional ELOs [64]. ELO5 synthesizes very long-chain FAs (VLCFAs) in T. cruzi, extending C18 to C26. The major product of ELO5 is C24, which is part of the GPI-anchors of infective trypomastigotes $[66,67]$, while C26 seems to be involved in the synthesis of sphingolipids (SLs) [68]. In L. major, ELO5 and ELO6 are involved in the extension of polyunsaturated FAs [69]. Moreover, ELO3.3, ELO4.2, and ELO4.3 expression is upregulated in L. major nectomonad promastigotes, indicating that biosynthesis of FAs increases in response to deprivation and stress conditions at this parasite life stage [70]. Noteworthily, the nectomonad promastigotes are the migratory forms found in the sand fly vector that will attach to the midgut epithelium of the insect mediating parasite establishment rather than expulsion, and L. major lipophosphoglycan (LPG) is the parasite surface molecule responsible for attachment [71].

Despite the unconventional ELO pathway, T. brucei and Leishmania spp. also use a mitochondrial type II FA synthesis pathway (FAS II) [72-74]. Unlike the cytosolic FAS I pathway, the mitochondrial FAS II relies on separate polypeptides that mediate the synthesis of caprylate (C8) and palmitate (C16; Figure 1A, 1B) [73]. Caprylate is a precursor of lipoic acid (LA) synthesis, an important cofactor of mitochondrial pyruvate dehydrogenase. In another study, researchers identified three $L$. major genes coding for at least two of the four enzymes involved in the FAS II pathway. Two of these $L$. major genes were shown to encode the 3hydroxyacyl-ACP dehydratase, but the evolutionary advantages of this gene duplication are not yet clear [74]. In $T$. cruzi, however, no gene related to the mitochondrial FAS II system has been reported.

Genes involved in modification of FAs were also found in trypanosomatids genome databases, including those involved in the cyclopropanation $[75,76]$ and synthesis of unsaturated FAs, which are FA molecules with one or more carbon-carbon double-bonds [77, 78]. For instance, Leishmania spp., except L. major, encode a cyclopropane FA synthase (CFAS), whereas Trypanosoma lack this gene [76]. In eukaryotes, CFAS is responsible for the addition of a methylene group to carbon-carbon double-bonds of unsaturated FAs in membrane lipids, forming cyclopropane FA (CFA). CFAs synthesis was shown to affect the cellular shape of $L$. mexicana and its resistance to acidic environments, although CFAS knockout does not appear to have any impact on parasite infectivity [75]. In L. infantum promastigotes, on the other hand, absence of CFAS significantly decreased activity of membrane transporters and diminished parasite burdens in the spleen and liver during in vivo infection [76].

Furthermore, desaturases were identified in $T$. brucei [79], L. major, and T. cruzi [77]. These enzymes were shown to be responsible for the synthesis of unsaturated 
and polyunsaturated FAs by insertion of double bonds at specific sites of the FA carbon skeleton [77]. In L. major, $\Delta 4$, $\Delta 5, \Delta 6, \Delta 12$, and $\Delta 15$ desaturases were characterized, whilst in $T$. brucei and $T$. cruzi, only $\Delta 4, \Delta 9$, and $\Delta 12$ desaturases were identified $[77,78]$ (Figure 1). Deuterium labeling studies revealed that $L$. mexicana amastigotes present high amounts of intracellular oleic (C18:1) and linoleic (C18:2) FAs, which are dependent on the presence of $\Delta 12$ desaturase activity [29]. Since, $\Delta 12$ desaturase activity is not detected in mammals, this enzyme was proposed as a promising drug target for novel chemotherapeutics against leishmaniases and trypanosomiases [80-82].

Acetyl-CoA is a key metabolite linking many biosynthetic and catabolic pathways, including biosynthesis and degradation of FAs. In particular, trypanosomatids have developed distinct mechanisms to obtain acetyl-CoA. This metabolite is mostly derived from threonine degradation [65, $83,84]$, glucose (via pyruvate), or leucine, and it is incorporated into FAs by the mitochondrial FAS II pathway or the ELO pathway in the ER [83] (Figure 1A and 1B). Threonine is salvaged from extracellular sources [85] and it is the preferred carbon source for lipid biosynthesis in T. brucei [84, 86]. On the other hand, genes involved in the threonine degradation pathway are absent in Leishmania spp. genomes, implying that Leishmania may incorporate other precursors to synthesize acetyl-CoA and acetate. For instance, in L. mexicana promastigotes, acetate is synthesized from aspartate and acetyl-CoA is produced by the catabolism of ketogenic amino acids [87].

Another difference to other eukaryotes is that the citrate/malate shuttle, which transfers acetyl-CoA from the mitochondrial matrix to the cytosol, is not essential in T. brucei PCFs. The inhibition of citrate lyase was shown to have no effect on the incorporation of radioactive-labeled glucose into lipids [85]. Alternatively, T. brucei uses a membrane carrier for translocation of acetate from the mitochondria to the cytosol, where acetate is converted back to acetyl-CoA by a cytosolic acetyl-CoA synthetase (ACS) at the expense of ATP. In mitochondria, acetate is synthesized from acetyl-CoA by the action of two mitochondrial enzymes, acetyl-CoA thioesterase $(\mathrm{ACH})$ and acetate:succinate CoA-transferase (ASCT), which is involved in substrate-level ATP production together with succinyl-CoA synthetase [88-91]. In the cytosol, acetyl-CoA is carboxylated to malonyl-CoA by acetyl-CoA carboxylase (ACC). Yet, the origin of malonyl-CoA required in the mitochondrion is unclear [92]. In T. brucei, ACC was shown to be required for elongation of FAs in both parasite life stages. In PCFs, ACC activity and protein levels were downregulated under lipidrich growth conditions. However, this was not observed in BSFs, most likely because these forms require constitutively active ACC for myristate synthesis and GPI-anchor assembly [93].

\section{LIPID BIOSYNTHESIS}

Upon synthesis, FAs can be incorporated into more complex molecules, such as PLs which are the major components of biological membranes in eukaryotes. Numerous studies on lipid composition of PCFs and BSFs of $T$. brucei have shown that phosphatidylethanolamine (PE) and phosphatidylcholine (PC) are the major classes of PLs in $T$. brucei (reviewed in [94]). A similar lipid profile was also observed in trypomastigotes and amastigotes of $T$. cruzi, and amastigotes and promastigotes of Leishmania donovani and $L$. infantum $[95,96]$. PE and PC are synthesized via the two branches of the Kennedy pathway (reviewed in [97]) that consists of three conserved enzymatic reactions. The first step of this pathway is catalyzed by a kinase, which promotes the phosphorylation of ethanolamine and choline. The second step is catalyzed by a cytidylyltransferase, forming the high energy intermediates CDPethanolamine and CDP-choline. And the third step is catalyzed by a phosphotransferase that transfers the ethanolamine and choline intermediates to DAG and alkylacylglycerol (AAG) [97]. The kinases of both branches of the Kennedy pathway were identified and biochemically characterized in T. brucei [98], as well as the cytidylyltransferase of the ethanolamine branch, shown to be essential in $T$. brucei BSFs [99]. Moreover, the phosphotransferase from the choline branch was localized to the ER, and the phosphotransferase from the ethanolamine branch was localized to a sub-compartment close to the nuclear membrane [100]. In L. infantum, the kinase from the choline branch was also shown to phosphorylate ethanolamine, albeit with much lower efficiency compared to choline [101]. Besides, two PE methyltransferases, which convert $P E$ into $P C$ through tri-methylation, were identified in the ER of L. major. Noteworthily, both enzymes are inhibited by the choline analogs miltefosine and hexadecyltrimethylammonium bromide, supporting their potential as drug targets [102]. Furthermore, it was shown that PC synthesis is essential for $L$. major promastigotes, but not for amastigotes [103]. To date, no components of the Kennedy pathway have been characterized in $T$. cruzi.

SLs are other major lipid components of trypanosomatids biological membranes. Genomic database searches identified most of the genes involved in the sphingolipid biosynthetic pathway in trypanosomatids [104]. The enzymes of the final step of this pathway, sphingolipid synthases (TbSLS1-4), were characterized in T. brucei [105]: TbSLS1 produces inositol phosphorylceramide (IPC), TbSLS2 produces ethanolamine phosphorylceramide (EPC), and both TbSLS3 and TbSLS4 produce sphingomyelin (SM) and EPC. Importantly, IPC and EPC are rare lipid species in mammalian hosts [106], hence, their synthesis pathways are potential targets for drug development. Furthermore, in $L$. major, the SL metabolic pathway can be redirected for production of the ethanolamine required for synthesis of PE by the Kennedy pathway [107] (for a more detailed review on SL and PL metabolism in Leishmania see [108]).

Sterols are other important membrane components that play a crucial role in regulating membrane dynamics and fluidity. Metabolomic analyses revealed ergosterol as the major cellular sterol in Leishmania [109]. Genome database searches identified putative genes of the isoprenoid pathway potentially involved in the synthesis of ergosterol in T. brucei, T. cruzi, and L. major [110]. Proteomic analysis 
of purified glycosomes from $T$. cruzi epimastigotes revealed the compartmentalization of several enzymes associated with the isoprenoid pathway, also referred as the mevalonate pathway [111]. Other studies also located the enzymes of the early steps of isoprenoid pathway in the glycosomes of T. brucei and L. major [112]. Compartmentalization of the isoprenoid pathway may have a role on the modulation of sterol synthesis throughout parasite differentiation, as observed for other pathways [113]. Accordingly, significant differences in sterol composition were observed between $L$. infantum procyclic and metacyclic promastigotes [114].

\section{FATTY ACID OXIDATION}

FAs can also be oxidized to provide energy through the $\beta$-oxidation pathway that may occur in the mitochondria or in the glycosomes of trypanosomatids (Figure 1) [110, 111, $115,116]$. Glycosomes are unique trypanosomatid organelles related to eukaryotes' peroxisomes. Uptake of longchain fatty acyl-CoA esters into peroxisomes was shown to be mediated by the peroxisomal ATP-binding cassette protein subfamily $D(A B C D)$ in plants, and by the peroxisomal long-chain fatty acid import proteins 1 and 2 (PXA1 and PXA2) in yeast [117-119]. Similarly, glycosomal $A B C$ transporters 1 to 3 (GAT 1-3), homologs of the peroxisomal $A B C$ transporters, were identified in the glycosomal membrane of $T$. brucei $[120,121]$. The knockdown of GAT1 by RNA interference (RNAi) in PCFs of $T$. brucei showed a significant increase of linoleate (C18:2) and a decrease of glycosomal oleoyl (C18:1)-CoA incorporation, supporting GAT1 role in FAs transport from the cytosol into the glycosome [122].

Noteworthily, stage-specific changes in carbon metabolism were observed in Leishmania. These studies revealed that $L$. mexicana intracellular amastigotes exhibit reduced glucose consumption compared to promastigotes, which was compensated by increased $\beta$-oxidation of FAs [113]. In addition, enzymes involved in the $\beta$-oxidation of FAs were shown to be upregulated in $L$. donovani and $L$. major amastigotes [123]. On the other hand, trypanosomes exhibit reduced or undetectable oxidation of FAs during their life cycles. Yet, $T$. brucei forms found in the adipose tissue have a distinct metabolic profile with upregulation of the $\beta$-oxidation pathway [24]. T. cruzi can also be found in the adipose tissue [124], often near lipid droplets, suggesting that they may also be exploiting local lipolysis to match their energy requirements [27]. Clinically, the findings revealing the adipose tissue as a novel niche for trypanosomes may help understand some cases of relapse, since this tissue is known for its low perfusion for drugs [125, 126].

\section{FATTY ACID REMODELING}

GPI-anchors are lipid-conjugated molecules present in all eukaryotes yet appear in a higher frequency in protozoa [127]. The main role of GPI-anchors is to attach enzymes, receptors, and other macromolecules to the plasma membrane [127]. In protozoan parasites, most GPI-anchors share a common backbone structure composed of EtN-P-

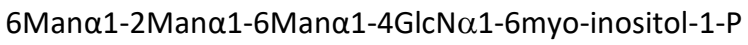
lipid, with additional mannosylation or phosphorylation $[127,128]$. Within this core structure, several lipid configurations and modifications can be found depending on the parasite species and/or the life stage. Such modifications include the inositol 2-O-acylation in $T$. brucei PCFs, the presence of a chain branch at the $\mathrm{C} 3$ position of Mannose I in T. brucei VSG GPI-anchors, and the hybrid type Glycoinositol Phospholipids (GIPLs) in Leishmania [128]. Besides, $\mathrm{GPI}$-anchors can vary in PL composition, length, and degree of saturation in the hydrocarbon chains [128]. Unlike mammalian GPI-anchors, trypanosomatids GPI-anchors display typical FA acid remodeling. For example, T. brucei, $T$. congolense, and T. equiperdum GPI-anchors are exclusively di-myristoylated, while Leishmania GP63 displays monomyristoylated GPI-anchors (reviewed in [19]).

In trypanosomes and Leishmania, GPI-anchored glycoconjugates extensively coat the plasma membrane and are involved in several aspects of the host-parasite interaction. Such aspects include survival, host immune response evasion, adhesion and invasion of host cells, and pathogenesis [127]. In addition, the GPI-anchored procyclin proteins may protect $T$. brucei against proteolytic attack in the tsetse midgut [129]. About ten million copies of VSGs were found to cover each BSF of T. brucei, and these VSGs are attached to the lipid bilayer of the parasite plasma membrane via a GPI-anchor containing exclusively two myristate molecules $[73,130]$. T. brucei GPI-VSGs were shown to induce expression of pro-inflammatory genes, such as TNF- $\alpha$, IL-6, and GM-CSF [131]. T. cruzi GPI-anchors were also found to be potent proinflammatory molecules as they trigger the production of nitric oxide, $\mathrm{IL}-12$ and TNF $-\alpha$ by macrophages $[66,132]$. In the case of $L$. mexicana, GIPLs biosynthesis requires FA remodeling. Similar to what was shown in $T$. brucei, this FA remodeling reactions are COA and ATP-dependent, and occur on pre-existing but not on de novo synthesized GIPLs [133].

\section{LIPID AND FATTY ACID METABOLISMS AS DRUG TARGETS}

There are few currently available drugs to treat leishmaniases and trypanosomiases [7, 134, 135]. Among the registered anti-Leishmania drugs, Miltefosine, Amphotericin B, and pentavalent antimonials $\left(\mathrm{Sb}^{\mathrm{V}}\right)$ target lipid-related pathways (Table 1). Miltefosine, a PC analog, was originally developed as an antitumoral drug (reviewed in [136]) and is the only oral anti-Leishmania drug approved by the United States Food and Drug Administration (U.S. FDA). Although its specific mechanism of action is still unclear, PL quantification of $L$. donovani promastigotes treated with Miltefosine showed a reduction of parasites PC levels and an increase of PE levels [137], suggesting that Miltefosine may interfere with the PE methyltransferase that converts PE into PC. Miltefosine also impairs mitochondrial function and disturbes calcium homeostasis in L. donovani [138140]. Moreover, Miltefosine-treated parasites showed higher amounts of cholesterol than non-treated parasites 
TABLE 1. Registered drugs and potential inhibitors targeting trypanosomatids' FA and lipid-related pathways.

\begin{tabular}{|c|c|c|}
\hline Target pathway & Inhibitor/Drug & Organism \\
\hline \multirow{2}{*}{ Ergosterol metabolism } & Amphotericin B deoxycholate ${ }^{a}$ & \multirow{2}{*}{ Leishmania $[142,143,145]$} \\
\hline & Liposomal Amphotericin $\mathrm{B}^{a}$ & \\
\hline Ergosterol synthesis & 26-Fluorolanosterol (26-FL) & T. brucei $[161]$ \\
\hline FA $\beta$-oxidation & Sodium stibogluconate ${ }^{a}$ & Leishmania [147] \\
\hline FA synthesis & Thiolactomycin & $\begin{array}{l}\text { T. brucei, T. cruzi and L. donovani } \\
\text { [150] }\end{array}$ \\
\hline PL synthesis & Miltefosine ${ }^{a}$ & Leishmania [136] \\
\hline \multirow[t]{2}{*}{ Sterol metabolism } & Risedronate & T. cruzi $[160]$ \\
\hline & Imipramine & Leishmania [137, 159] \\
\hline \multirow{3}{*}{ SL metabolism } & Myriocin & L. braziliensis [157] \\
\hline & Tamoxifen & L. amazonensis and L. major [158] \\
\hline & 3-(oxazolo[4,5-b]pyridine-2-yl)anilide (OXPA) & T. brucei [156] \\
\hline \multirow{3}{*}{$\Delta 9$ desaturase } & 10-thiastearic acid & T. cruzi $[82]$ \\
\hline & Isoxyl & T. cruzi $[82]$ \\
\hline & GS-456332 & T. brucei and T. cruzi [81] \\
\hline \multirow[t]{2}{*}{$\Delta 12$ desaturase } & Stearolic acid & T. brucei and T. cruzi [81] \\
\hline & 12- and 13-thiastearic acid & T. brucei [155] and T. cruzi [82] \\
\hline
\end{tabular}

${ }^{a}$ - Registered for clinical use. PL - phospholipid; FA - fatty acid; SL - sphingolipid.

[137], suggesting that Miltefosine may also promote cholesterol uptake. Amphotericin B deoxycholate (AmB) targets ergosterol precursors leading to disruption of Leishmania membrane [141, 142], and it is the preferential treatment for patients co-infected with HIV and visceral leishmaniasis [143, 144]. Its lipid formulation, Liposomal Amphotericin B (AmBisome ${ }^{\circledR}$; LAmB) is a less-toxic alternative $[143,145]$. This formulation corresponds to AmB solubilized in unilamellar vesicles composed of cholesterol and PLs, which leads to increased and longer-lasting efficacy [143]. Pentavalent antimonials $\left(\mathrm{Sb}^{\mathrm{v}}\right)$ are another group of compounds widely used to treat leishmaniases and appear to disturb FAs synthesis [146]. However, their mechanism of action is also still unclear. In particular, among the $\mathrm{Sb}^{\mathrm{V}}$, sodium stibogluconate was proposed to inhibit glucose catabolism and FAs $\beta$-oxidation in Leishmania [147]. Other metabolic studies revealed major differences in lipid metabolism of antimonial-resistant parasites, indicating that these pathways may be related to parasite drug resistance [148].

Efforts are being made to search for other molecules targeting FA and lipid metabolism that could potentially arise as better alternative drugs against leishmaniases and trypanosomiases (Table 1). For instance, in vitro treatment of $T$. cruzi with ketoconazole reduced the activity of $\Delta 9$ desaturase by $90 \%$ [149]. Thiolactomycin, an inhibitor of the condensation step of bacterial FAS II that has also been tested as a potential antimalarial drug [150-152], inhibited
T. brucei FAs synthesis and parasite growth in culture [153]. Thiolactomycin analogues were also able to inhibit growth of T. brucei, T. cruzi, and L. donovani [150]. Other studies with $T$. cruzi epimastigotes showed that thiastearic acid (TS) isomers inhibit $\Delta 9$ and $\Delta 12$ desaturases. $\Delta 9$ desaturase was inhibited by 10 -TS, while $\Delta 12$ was inhibited by both 12- and 13-TS [82]. In addition, isoxyl, a thiourea derivative that inhibits $M$. tuberculosis $\Delta 9$ desaturase [154], reduced the percentage of unsaturated FAs in T. cruzi epimastigotes [82]. In T. brucei,12- and 13-TS also inhibited in vitro growth of PCFs and BSFs [155]. Moreover, stearolic acid effectively inhibited $\Delta 12$ desaturases of $T$. cruzi epimastigotes and T. brucei BSFs, and GS-456332, a known inhibitor of human $\Delta 9$ desaturase, inhibited in vitro growth of both parasites. The combination of these FAs desaturases inhibitors showed a synergistic effect on trypanosomes, with decreased EC50 values [81].

SL metabolism is another potential drug target for development of anti-trypanosomatids therapy. In particular, metabolomic studies indicate that ceramides, central components of SLs, accumulate in BSFs of $T$. brucei treated with the anti-trypanosomal compound 3-(oxazolo[4,5b]pyridine-2-yl)anilide (OXPA) [156]. In Leishmania braziliensis promastigotes, it was shown that myriocin reduces synthesis of IPC, which is the major SL expressed in this parasite developmental form. Myriocin inhibited Leishmania growth by $52 \%$ and caused morphological alterations [157]. In L. amazonensis, IPC and phosphatidylin- 
ositol (PI) levels were reduced by the anticancer drug tamoxifen. Tamoxifen also inhibited $L$. major IPC synthase in in vitro assays [158]. Imipramine, a common antidepressant, also exhibited antileishmanial activity through inhibition of sterol biosynthesis. Noteworthily, imipramine combined with miconazole, a known inhibitor of ergosterol synthesis in fungi, had an additive effect improving their leishmanicidal activity [159]. Risedronate is another potential drug that targets $T$. cruzi sterol metabolism, affecting parasites growth and the structure of mitochondria and reservosomes [160]. Lastly, T. brucei ergosterol biosynthesis was inhibited by 26 -Fluorolanosterol (26-FL) impairing PCFs and BSFs in vitro growth [161]. Considering their potential to target FA and lipid metabolism pathways in vitro, further in vivo studies with all these inhibitors will indicate their prospects for clinical use and may unveil better chemotherapeutics against trypanosomatids.

\section{SUMMARY AND PERSPECTIVES}

Lipids and FAs are among the nutrients that trypanosomatid parasites rely on their hosts to survive and replicate. PLs, SLs and sterols play important roles in membrane biology of trypanosomatids. The synthesis of PLs species is essential, and it can also be redirected to SL synthesis. FAs are the building blocks of PLs, one of the major components of eukaryotes' cell membranes. The degree of unsaturation and the presence of cyclopropanation in the FAs acyl chains provide mechanisms to adjust membrane fluidity. Besides, FAs are components of membrane anchors for a large diversity of surface glycoproteins in trypanosomatids, which have essential roles in host-parasite interaction. Long-chain modified FAs, such as prostaglandins stored in LDs, surface glycoproteins, and phosphoglycans also play important roles in host-parasite interaction and immune response. Furthermore, FAs are part of these parasites strategies to adapt to the different environments during their life cycles, serving as an energy source in specific life stages. Despite all the central roles played by FAs on trypanosomatids biology, the parasites mechanisms to scavenge

\section{REFERENCES}

1. Hong A, Zampieri RA, Shaw JJ, Floeter-Winter LM, Laranjeira-Silva MF (2020). One Health Approach to Leishmaniases: Understanding the Disease Dynamics through Diagnostic Tools. Pathogens 9(10): 809. doi: 10.3390/pathogens9100809

2. Büscher $P$, Cecchi G, Jamonneau V, Priotto G (2017). Human African trypanosomiasis. Lancet 390(10110): 2397-2409. doi: 10.1016/S01406736(17)31510-6

3. Caljon G, Van Reet N, De Trez C, Vermeersch M, Pérez-Morga D, Van Den Abbeele J (2016). The Dermis as a Delivery Site of Trypanosoma brucei for Tsetse Flies. PLoS Pathog 12(7): e1005744. doi: 10.1371/journal.ppat.1005744

4. Rassi A, Marin-Neto JA (2010). Chagas disease. Lancet 375(9723): 1388-1402. doi: 10.1016/S0140-6736(10)60061-X

5. Antinori S, Galimberti L, Bianco R, Grande R, Galli M, Corbellino M (2017). Chagas disease in Europe: A review for the internist in the globalized world. Eur J Intern Med 43: 6-15. doi: 10.1016/j.ejim.2017.05.001
FAs from the host are still poorly understood. Also, there is a knowledge gap regarding FA and lipid metabolic pathways between $T$. cruzi, T. brucei, and Leishmania spp. Nevertheless, these pathways have been explored for the design of new anti-trypanosomatids drugs. Several desaturase inhibitors were identified in recent years, however, most of them have not yet been tested in vivo. Therefore, elucidating the peculiarities of lipid and FA metabolism of these parasites will continue to be a promising route for the development of novel therapeutic strategies against trypanosomiases and leishmaniases.

\section{ACKNOWLEDGMENTS}

We would like to thank Ahyun Hong for revising English writing. This work was supported by grants from the São Paulo Research Foundation (FAPESP) (\#2019/19968-1 and \#2019/23933-3). MFLS acknowledges a FAPESP young researcher fellowship (\#2018/15971-5). RKS receives a research fellowship from Conselho Nacional de Desenvolvimento Científico e Tecnológico (CNPq \#308119/2020-7).

\section{CONFLICT OF INTEREST}

The authors declare that they have no known competing financial interests or personal relationships that could have appeared to influence the work reported in this paper.

\section{COPYRIGHT}

(C) 2021 Parreira de Aquino et al. This is an open-access article released under the terms of the Creative Commons Attribution (CC BY) license, which allows the unrestricted use, distribution, and reproduction in any medium, provided the original author and source are acknowledged.

Please cite this article as: Giovana Parreira de Aquino, Marco Antonio Mendes Gomes, Roberto Köpke Salinas and Maria Fernanda Laranjeira-Silva (2021). Lipid and fatty acid metabolism in trypanosomatids. Microbial Cell 8(11): 262-275. doi: 10.15698/mic2021.11.764

6. Manne-Goehler J, Umeh CA, Montgomery SP, Wirtz VJ (2016). Estimating the Burden of Chagas Disease in the United States. PLoS Negl Trop Dis 10(11): e0005033. doi: 10.1371/journal.pntd.0005033

7. World Health Organization (2021). Chagas disease (also known as American trypanosomiasis). Avalaible at: https://www.who.int/newsroom/fact-sheets/detail/chagas-disease-(american-trypanosomiasis) [Accessed 04.04.2021]

8. Mattos EC, Meira-Strejevitch CDS, Marciano MAM, Faccini CC, Lourenço AM, Pereira-Chioccola VL (2017). Molecular detection of Trypanosoma cruzi in acai pulp and sugarcane juice. Acta Trop 176: 311315. doi: 10.1016/j.actatropica.2017.08.025

9. Ferreira RTB, Cabral ML, Martins RS, Araujo PF, da Silva SA, Britto C, Branquinho MR, Cardarelli-Leite P, Moreira OC (2018). Detection and genotyping of Trypanosoma cruzi from açai products commercialized in Rio de Janeiro and Pará, Brazil. Parasit Vectors 11(1): 233. doi: 10.1186/s13071-018-2699-6 
10. Burza S, Croft SL, Boelaert M (2018). Leishmaniasis. Lancet 392(10151): 951-970. doi: 10.1016/S0140-6736(18)31204-2

11. Alvar J, Vélez ID, Bern C, Herrero M, Desjeux P, Cano J, Jannin J, den Boer M, Team WLC (2012). Leishmaniasis worldwide and global estimates of its incidence. PLoS One 7(5): e35671. doi: 10.1371/journal.pone.0035671

12. World Health Organization (2021). Leishmaniasis. Avalaible at: https://www.who.int/news-room/fact-sheets/detail/leishmaniasis [Acessed 04.04.2021]

13. Zuzarte-Luís V, Mota MM (2018). Parasite Sensing of Host Nutrients and Environmental Cues. Cell Host Microbe 23(6): 749-758. doi: 10.1016/j.chom.2018.05.018

14. Zilberstein D, Shapira M (1994). The role of $\mathrm{pH}$ and temperature in the development of Leishmania parasites. Annu Rev Microbiol 48: 449-470. doi: 10.1146/annurev.mi.48.100194.002313

15. Landfear SM (2011). Nutrient transport and pathogenesis in selected parasitic protozoa. Eukaryot Cell 10(4): 483-493. doi: 10.1128/EC.00287-10

16. Pereira MG, Nakayasu ES, Sant'Anna C, De Cicco NN, Atella GC, de Souza W, Almeida IC, Cunha-e-Silva N (2011). Trypanosoma cruzi epimastigotes are able to store and mobilize high amounts of cholesterol in reservosome lipid inclusions. PLoS One 6(7): e22359. doi: 10.1371/journal.pone.0022359

17. Stijlemans B, Beschin A, Magez S, Van Ginderachter JA, De Baetselier P (2015). Iron Homeostasis and Trypanosoma brucei Associated Immunopathogenicity Development: A Battle/Quest for Iron. Biomed Res Int 2015: 819389. doi: 10.1155/2015/819389

18. Hood MI, Skaar EP (2012). Nutritional immunity: transition metals at the pathogen-host interface. Nat Rev Microbiol 10(8): 525-537. doi: $10.1038 /$ nrmicro2836

19. Goldston AM, Sharma AI, Paul KS, Engman DM (2014). Acylation in trypanosomatids: an essential process and potential drug target. Trends Parasitol 30(7): 350-360. doi: 10.1016/j.pt.2014.05.003

20. Guler JL, Kriegova E, Smith TK, Lukes J, Englund PT (2008). Mitochondrial fatty acid synthesis is required for normal mitochondrial morphology and function in Trypanosoma brucei. Mol Microbiol 67(5): 1125-1142. doi: 10.1111/j.1365-2958.2008.06112.x

21. Paul KS, Jiang D, Morita YS, Englund PT (2001). Fatty acid synthesis in African trypanosomes: a solution to the myristate mystery. Trends Parasitol 17(8): 381-387. doi: 10.1016/s1471-4922(01)01984-5

22. Paloque L, Perez-Berezo T, Abot A, Dalloux-Chioccioli J, BourgeadeDelmas S, Le Faouder P, Pujo J, Teste MA, François JM, Schebb NH, Mainka M, Rolland C, Blanpied C, Dietrich G, Bertrand-Michel J, Deraison C, Valentin A, Cenac N (2019). Polyunsaturated fatty acid metabolites: biosynthesis in Leishmania and role in parasite/host interaction. J Lipid Res 60(3): 636-647. doi: 10.1194/jlr.M091736

23. Tomiotto-Pellissier F, Bortoleti BTDS, Assolini JP, Gonçalves MD, Carloto ACM, Miranda-Sapla MM, Conchon-Costa I, Bordignon J, Pavanelli WR (2018). Macrophage Polarization in Leishmaniasis: Broadening Horizons. Front Immunol 9: 2529. doi: 10.3389/fimmu.2018.02529

24. Trindade S, Rijo-Ferreira F, Carvalho $T$, Pinto-Neves D, Guegan F, Aresta-Branco F, Bento F, Young SA, Pinto A, Van Den Abbeele J, Ribeiro RM, Dias S, Smith TK, Figueiredo LM (2016). Trypanosoma brucei Parasites Occupy and Functionally Adapt to the Adipose Tissue in Mice. Cell Host Microbe 19(6): 837-848. doi: 10.1016/j.chom.2016.05.002

25. Berman JD, Gallalee JV, Best JM, Hill T (1987). Uptake, distribution, and oxidation of fatty acids by Leishmania mexicana amastigotes. J Parasitol 73(3): 555-560. doi: 10.2307/3282136
26. Wood DE (1975). Trypanosoma cruzi: fatty acid metabolism in vitro. Exp Parasitol 37(1): 60-66. doi: 10.1016/0014-4894(75)90052-1

27. Combs TP, Nagajyothi, Mukherjee $S$, de Almeida CJ, Jelicks LA Schubert W, Lin $Y$, Jayabalan DS, Zhao D, Braunstein VL, LandskronerEiger S, Cordero A, Factor SM, Weiss LM, Lisanti MP, Tanowitz HB, Scherer PE (2005). The adipocyte as an important target cell for Trypanosoma cruzi infection. J Biol Chem 280(25): 24085-24094. doi: 10.1074/jbc.M412802200

28. de Souza W, Sant'Anna C, Cunha-e-Silva NL (2009). Electron microscopy and cytochemistry analysis of the endocytic pathway of pathogenic protozoa. Prog Histochem Cytochem 44(2): 67-124. doi: 10.1016/j.proghi.2009.01.001

29. Kloehn J, Saunders EC, O'Callaghan S, Dagley MJ, McConville MJ (2015). Characterization of metabolically quiescent Leishmania parasites in murine lesions using heavy water labeling. PLoS Pathog 11(2): e1004683. doi: 10.1371/journal.ppat.1004683

30. Coppens I, Opperdoes FR, Courtoy PJ, Baudhuin P (1987). Receptor-mediated endocytosis in the bloodstream form of Trypanosoma brucei. J Protozool 34(4): 465-473. doi: 10.1111/j.15507408.1987.tb03216.x

31. Coppens I, Levade T, Courtoy PJ (1995). Host plasma low density lipoprotein particles as an essential source of lipids for the bloodstream forms of Trypanosoma brucei. J Biol Chem 270(11): 57365741. doi: $10.1074 / j b c .270 .11 .5736$

32. De Cicco NN, Pereira MG, Corrêa JR, Andrade-Neto VV, Saraiva FB, Chagas-Lima AC, Gondim KC, Torres-Santos EC, Folly E, Saraiva EM, Cunha-E-Silva NL, Soares MJ, Atella GC (2012). LDL uptake by Leishmania amazonensis: involvement of membrane lipid microdomains. Exp Parasitol 130(4): 330-340. doi: 10.1016/j.exppara.2012.02.014

33. Soares MJ, de Souza W (1991). Endocytosis of gold-labeled proteins and LDL by Trypanosoma cruzi. Parasitol Res 77(6): 461-468. doi: 10.1007/BF00928410

34. Lee MG, Yen FT, Zhang Y, Bihain BE (1999). Acquisition of lipoproteins in the procyclic form of Trypanosoma brucei. Mol Biochem Parasitol 100(2): 153-162. doi: 10.1016/s0166-6851(99)00009-2

35. Prioli RP, Rosenberg I, Shivakumar S, Pereira ME (1988). Specific binding of human plasma high density lipoprotein (cruzin) to Trypanosoma cruzi. Mol Biochem Parasitol 28(3): 257-263. doi: 10.1016/01666851(88)90010-2

36. Gillett MP, Owen JS (1992). Characteristics of the binding of human and bovine high-density lipoproteins by bloodstream forms of the African trypanosome, Trypanosoma brucei brucei. Biochim Biophys Acta 1123(3): 239-248. doi: 10.1016/0005-2760(92)90002-d

37. Uttaro AD (2014). Acquisition and biosynthesis of saturated and unsaturated fatty acids by trypanosomatids. Mol Biochem Parasitol 196(1): 61-70. doi: 10.1016/j.molbiopara.2014.04.001

38. Roberts CW, McLeod R, Rice DW, Ginger M, Chance ML, Goad LJ (2003). Fatty acid and sterol metabolism: potential antimicrobial targets in apicomplexan and trypanosomatid parasitic protozoa. Mol Biochem Parasitol 126(2): 129-142. doi: 10.1016/s01666851(02)00280-3

39. Bowes AE, Samad AH, Jiang P, Weaver B, Mellors A (1993). The acquisition of lysophosphatidylcholine by African trypanosomes. J Biol Chem 268(19): 13885-13892. doi: 10.1016/s0021-9258(19)85185-2

40. Porfido JL, Alvite G, Silva V, Kennedy MW, Esteves A, Corsico B (2012). Direct interaction between EgFABP1, a fatty acid binding protein from Echinococcus granulosus, and phospholipid membranes. PLoS Negl Trop Dis 6(11): e1893. doi: 10.1371/journal.pntd.0001893

41. Brito CF, Oliveira GC, Oliveira SC, Street M, Riengrojpitak S, Wilson RA, Simpson AJ, Correa-Oliveira R (2002). Sm14 gene expression in 
different stages of the Schistosoma mansoni life cycle and immunolocalization of the Sm14 protein within the adult worm. Braz J Med Biol Res 35(3): 377-381. doi: 10.1590/s0100-879x2002000300014

42. Ibáñez-Shimabukuro $M$, Rey-Burusco MF, Gabrielsen $M$, Franchini GR, Riboldi-Tunnicliffe A, Roe AJ, Griffiths K, Cooper A, Córsico B, Kennedy MW, Smith BO (2019). Structure and ligand binding of Asp18, an extracellular fatty acid binding protein from the eggs of a parasitic nematode. Biosci Rep 39(7): BSR20191292. doi: 10.1042/BSR20191292

43. Shepard W, Haouz A, Graña M, Buschiazzo A, Betton JM, Cole ST, Alzari PM (2007). The crystal structure of Rv0813c from Mycobacterium tuberculosis reveals a new family of fatty acid-binding proteinlike proteins in bacteria. J Bacteriol 189(5): 1899-1904. doi: 10.1128/JB.01435-06

44. Parsons JB, Broussard TC, Bose JL, Rosch JW, Jackson P, Subramanian C, Rock CO (2014). Identification of a two-component fatty acid kinase responsible for host fatty acid incorporation by Staphylococcus aureus. Proc Natl Acad Sci U S A 111(29): 10532-10537. doi: 10.1073/pnas.1408797111

45. Parsons JB, Frank MW, Jackson P, Subramanian C, Rock CO (2014). Incorporation of extracellular fatty acids by a fatty acid kinasedependent pathway in Staphylococcus aureus. Mol Microbiol 92(2): 234-245. doi: 10.1111/mmi.12556

46. Gullett JM, Cuypers MG, Frank MW, White SW, Rock CO (2019). A fatty acid-binding protein of Streptococcus pneumoniae facilitates the acquisition of host polyunsaturated fatty acids. J Biol Chem 294(44): 16416-16428. doi: 10.1074/jbc.RA119.010659

47. Cuypers MG, Subramanian C, Gullett JM, Frank MW, White SW, Rock CO (2019). Acyl-chain selectivity and physiological roles of. J Biol Chem 294(1): 38-49. doi: 10.1074/jbc.RA118.006160

48. Gullett JM, Cuypers MG, Frank MW, White SW, Rock CO (2019). A fatty acid-binding protein of. J Biol Chem 294(44): 16416-16428. doi: 10.1074/jbc.RA119.010659

49. Storch J, Thumser AE (2010). Tissue-specific functions in the fatty acid-binding protein family. J Biol Chem 285(43): 32679-32683. doi: 10.1074/jbc.R110.135210

50. Ramos CR, Spisni A, Oyama S, Sforça ML, Ramos HR, Vilar MM, Alves AC, Figueredo RC, Tendler M, Zanchin NI, Pertinhez TA, Ho PL (2009). Stability improvement of the fatty acid binding protein Sm14 from S. mansoni by Cys replacement: structural and functional characterization of a vaccine candidate. Biochim Biophys Acta 1794(4): 655662. doi: 10.1016/j.bbapap.2008.12.010

51. Jakobsson E, Alvite G, Bergfors T, Esteves A, Kleywegt GJ (2003). The crystal structure of Echinococcus granulosus fatty-acid-binding protein 1. Biochim Biophys Acta 1649(1): 40-50. doi: 10.1016/s15709639(03)00151-1

52. Pereira MG, Visbal G, Salgado LT, Vidal JC, Godinho JL, De Cicco NN, Atella GC, de Souza W, Cunha-e-Silva N (2015). Trypanosoma cruzi Epimastigotes Are Able to Manage Internal Cholesterol Levels under Nutritional Lipid Stress Conditions. PLoS One 10(6): e0128949. doi: 10.1371/journal.pone.0128949

53. Soares MJ, Souto-Padrón T, Bonaldo MC, Goldenberg S, de Souza W (1989). A stereological study of the differentiation process in Trypanosoma cruzi. Parasitol Res 75(7): 522-527. doi: 10.1007/BF00931160

54. Flaspohler JA, Jensen BC, Saveria T, Kifer CT, Parsons M (2010). A novel protein kinase localized to lipid droplets is required for droplet biogenesis in trypanosomes. Eukaryot Cell 9(11): 1702-1710. doi: 10.1128/EC.00106-10

55. Rabhi S, Rabhi I, Trentin B, Piquemal D, Regnault B, Goyard S, Lang T, Descoteaux A, Enninga J, Guizani-Tabbane L (2016). Lipid Droplet
Formation, Their Localization and Dynamics during Leishmania major Macrophage Infection. PLoS One 11(2): e0148640. doi 10.1371/journal.pone.0148640

56. Soares MJ, De Souza MF, De Souza W (1987). Ultrastructural visualization of lipids in trypanosomatids. J Protozool 34(2): 199-203. doi: 10.1111/j.1550-7408.1987.tb03160.x

57. Ohsaki Y, Suzuki M, Fujimoto $T$ (2014). Open questions in lipid droplet biology. Chem Biol 21(1): 86-96. doi: 10.1016/j.chembiol.2013.08.009

58. Pereira MG, Visbal G, Costa TFR, Frases S, de Souza W, Atella G, Cunha-E-Silva N (2018). Trypanosoma cruzi epimastigotes store cholesteryl esters in lipid droplets after cholesterol endocytosis. Mol Biochem Parasitol 224: 6-16. doi: 10.1016/j.molbiopara.2018.07.004

59. Vallochi AL, Teixeira L, Oliveira KDS, Maya-Monteiro CM, Bozza PT (2018). Lipid Droplet, a Key Player in Host-Parasite Interactions. Front Immunol 9: 1022. doi: 10.3389/fimmu.2018.01022

60. Toledo DA, Roque NR, Teixeira L, Milán-Garcés EA, Carneiro AB, Almeida MR, Andrade GF, Martins JS, Pinho RR, Freire-de-Lima CG, Bozza PT, D'Avila H, Melo RC (2016). Lipid Body Organelles within the Parasite Trypanosoma cruzi: A Role for Intracellular Arachidonic Acid Metabolism. PLoS One 11(8): e0160433. doi: 10.1371/journal.pone.0160433

61. Araújo-Santos T, Rodríguez NE, Moura-Pontes S, Dixt UG, Abánades DR, Bozza PT, Wilson ME, Borges VM (2014). Role of prostaglandin F2 $\alpha$ production in lipid bodies from Leishmania infantum chagasi: insights on virulence. J Infect Dis 210(12): 1951-1961. doi: 10.1093/infdis/jiu299

62. Allmann S, Mazet M, Ziebart N, Bouyssou G, Fouillen L, Dupuy JW, Bonneu M, Moreau P, Bringaud F, Boshart M (2014). Triacylglycerol Storage in Lipid Droplets in Procyclic Trypanosoma brucei. PLoS One 9(12): e114628. doi: 10.1371/journal.pone.0114628

63. Dawoody Nejad L, Serricchio M, Jelk J, Hemphill A, Bütikofer P (2018). TbLpn, a key enzyme in lipid droplet formation and phospholipid metabolism, is essential for mitochondrial integrity and growth of Trypanosoma brucei. Mol Microbiol. doi: 10.1111/mmi.13976

64. Lee SH, Stephens JL, Paul KS, Englund PT (2006). Fatty acid synthesis by elongases in trypanosomes. Cell 126(4): 691-699. doi: 10.1016/j.cell.2006.06.045

65. Lee SH, Stephens JL, Englund PT (2007). A fatty-acid synthesis mechanism specialized for parasitism. Nat Rev Microbiol 5(4): 287297. doi: $10.1038 /$ nrmicro1617

66. Almeida IC, Camargo MM, Procópio DO, Silva LS, Mehlert A, Travassos LR, Gazzinelli RT, Ferguson MA (2000). Highly purified glycosylphosphatidylinositols from Trypanosoma cruzi are potent proinflammatory agents. EMBO J 19(7): 1476-1485. doi 10.1093/emboj/19.7.1476

67. Serrano AA, Schenkman S, Yoshida N, Mehlert A, Richardson JM, Ferguson MA (1995). The lipid structure of the glycosylphosphatidylinositol-anchored mucin-like sialic acid acceptors of Trypanosoma cruzi changes during parasite differentiation from epimastigotes to infective metacyclic trypomastigote forms. J Biol Chem 270(45): 27244-27253. doi: 10.1074/jbc.270.45.27244

68. Livore VI, Uttaro AD (2015). Biosynthesis of very long chain fatty acids in Trypanosoma cruzi. Parasitol Res 114(1): 265-271. doi: 10.1007/s00436-014-4188-y

69. Livore VI, Tripodi KE, Uttaro AD (2007). Elongation of polyunsaturated fatty acids in trypanosomatids. FEBS J 274(1): 264-274. doi: 10.1111/j.1742-4658.2006.05581.x

70. Inbar E, Hughitt VK, Dillon LA, Ghosh K, El-Sayed NM, Sacks DL (2017). The Transcriptome of Leishmania major Developmental Stages 
in Their Natural Sand Fly Vector. mBio 8(2): e00029-17. doi: 10.1128/mBio.00029-17

71. Sacks DL (2001). Leishmania-sand fly interactions controlling species-specific vector competence. Cell Microbiol 3(4): 189-196. doi: 10.1046/j.1462-5822.2001.00115.x

72. Autio KJ, Guler JL, Kastaniotis AJ, Englund PT, Hiltunen JK (2008). The 3-hydroxyacyl-ACP dehydratase of mitochondrial fatty acid synthesis in Trypanosoma brucei. FEBS Lett 582(5): 729-733. doi: 10.1016/j.febslet.2008.01.051

73. Stephens JL, Lee SH, Paul KS, Englund PT (2007). Mitochondrial fatty acid synthesis in Trypanosoma brucei. J Biol Chem 282(7): 44274436. doi: 10.1074/jbc.M609037200

74. Gurvitz A (2009). Identification of the Leishmania major proteins LmjF07.0430, LmjF07.0440, and LmjF27.2440 as components of fatty acid synthase II. J Biomed Biotechnol 2009: 950864 doi: 10.1155/2009/950864

75. Xu W, Mukherjee S, Ning Y, Hsu FF, Zhang K (2018). Cyclopropane fatty acid synthesis affects cell shape and acid resistance in Leishmania mexicana. Int J Parasitol 48(3-4): 245-256. doi: 10.1016/j.ijpara.2017.09.006

76. Oyola SO, Evans KJ, Smith TK, Smith BA, Hilley JD, Mottram JC, Kaye PM, Smith DF (2012). Functional analysis of Leishmania cyclopropane fatty acid synthetase. PLoS One 7(12): e51300. doi: 10.1371/journal.pone.0051300

77. Alloatti A, Uttaro AD (2011). Highly specific methyl-end fatty-acid desaturases of trypanosomatids. Mol Biochem Parasitol 175(2): 126132. doi: 10.1016/j.molbiopara.2010.10.006

78. Tripodi KE, Buttigliero LV, Altabe SG, Uttaro AD (2006). Functional characterization of front-end desaturases from trypanosomatids depicts the first polyunsaturated fatty acid biosynthetic pathway from a parasitic protozoan. FEBS J 273(2): 271-280. doi: 10.1111/j.17424658.2005.05049.x

79. Petrini GA, Altabe SG, Uttaro AD (2004). Trypanosoma brucei oleate desaturase may use a cytochrome b5-like domain in another desaturase as an electron donor. Eur J Biochem 271(6): 1079-1086. doi: 10.1111/j.1432-1033.2004.04005.x

80. Lee JM, Lee H, Kang S, Park WJ (2016). Fatty Acid Desaturases, Polyunsaturated Fatty Acid Regulation, and Biotechnological Advances. Nutrients 8(1): 23. doi: 10.3390/nu8010023

81. Alloatti A, Tripodi KE, Uttaro AD (2013). Synergistic effect of inhibitors of fatty acid desaturases on Trypanosoma parasites. Parasitol Res. doi: 10.1007/s00436-013-3508-y

82. Alloatti A, Testero SA, Uttaro AD (2009). Chemical evaluation of fatty acid desaturases as drug targets in Trypanosoma cruzi. Int J Parasitol 39(9): 985-993. doi: 10.1016/j.ijpara.2009.01.011

83. Gilbert RJ, Klein RA, Miller PG (1983). The role of threonine in the metabolism of acetyl coenzyme a by Trypanosoma brucei brucei. Comp Biochem Physiol B 74(2): 277-281. doi: 10.1016/03050491(83)90012-3

84. Millerioux $Y$, Mazet M, Bouyssou G, Allmann S, Kiema TR, Bertiaux E, Fouillen L, Thapa C, Biran M, Plazolles N, Dittrich-Domergue F, Crouzols A, Wierenga RK, Rotureau B, Moreau P, Bringaud F (2018). De novo biosynthesis of sterols and fatty acids in the Trypanosoma brucei procyclic form: Carbon source preferences and metabolic flux redistributions. PLoS Pathog 14(5): e1007116. doi: 10.1371/journal.ppat.1007116

85. Rivière L, Moreau $\mathrm{P}$, Allmann $\mathrm{S}$, Hahn $\mathrm{M}$, Biran $\mathrm{M}$, Plazolles $\mathrm{N}$, Franconi JM, Boshart M, Bringaud F (2009). Acetate produced in the mitochondrion is the essential precursor for lipid biosynthesis in pro- cyclic trypanosomes. Proc Natl Acad Sci U S A 106(31): 12694-12699. doi: 10.1073/pnas.0903355106

86. Klein RA, Linstead DJ (1976). Threonine as a perferred source of 2carbon units for lipid synthesis in Trypanosoma brucei. Biochem Soc Trans 4(1): 48-50. doi: 10.1042/bst0040048

87. Ginger ML, Chance ML, Goad $\sqcup$ (1999). Elucidation of carbon sources used for the biosynthesis of fatty acids and sterols in the trypanosomatid Leishmania mexicana. Biochem J 342 ( Pt 2): 397-405. doi: 10.1042/0264-6021:3420397

88. Van Hellemond JJ, Opperdoes FR, Tielens AG (1998). Trypanosomatidae produce acetate via a mitochondrial acetate:succinate CoA transferase. Proc Natl Acad Sci U S A 95(6): 3036-3041. doi: 10.1073/pnas.95.6.3036

89. Rivière L, van Weelden SW, Glass $P$, Vegh $P$, Coustou V, Biran M, van Hellemond JJ, Bringaud F, Tielens AG, Boshart M (2004). Acetyl:succinate CoA-transferase in procyclic Trypanosoma brucei. Gene identification and role in carbohydrate metabolism. J Biol Chem 279(44): 45337-45346. doi: 10.1074/jbc.M407513200

90. Millerioux $Y$, Morand $P$, Biran M, Mazet M, Moreau P, Wargnies M, Ebikeme C, Deramchia K, Gales L, Portais JC, Boshart M, Franconi JM, Bringaud $F$ (2012). ATP synthesis-coupled and -uncoupled acetate production from acetyl-CoA by mitochondrial acetate:succinate CoAtransferase and acetyl-CoA thioesterase in Trypanosoma. J Biol Chem 287(21): 17186-17197. doi: 10.1074/jbc.M112.355404

91. Mazet $M$, Morand $P$, Biran $M$, Bouyssou $G$, Courtois $P$, Daulouède $S$, Millerioux $Y$, Franconi JM, Vincendeau $P$, Moreau $P$, Bringaud $F$ (2013). Revisiting the central metabolism of the bloodstream forms of Trypanosoma brucei: production of acetate in the mitochondrion is essential for parasite viability. PLoS Negl Trop Dis 7(12): e2587. doi: 10.1371/journal.pntd.0002587

92. Vigueira PA, Paul KS (2011). Requirement for acetyl-CoA carboxylase in Trypanosoma brucei is dependent upon the growth environment. Mol Microbiol 80(1): 117-132. doi: 10.1111/j.13652958.2011.07563.x

93. Ray SS, Wilkinson CL, Paul KS (2018). Regulation of Trypanosoma brucei Acetyl Coenzyme A Carboxylase by Environmental Lipids. mSphere 3(4): e00164-18. doi: 10.1128/mSphere.00164-18

94. Smith TK, Bütikofer P (2010). Lipid metabolism in Trypanosoma brucei. Mol Biochem Parasitol 172(2): 66-79. doi 10.1016/j.molbiopara.2010.04.001

95. Gazos-Lopes F, Martin JL, Dumoulin PC, Burleigh BA (2017). Host triacylglycerols shape the lipidome of intracellular trypanosomes and modulate their growth. PLoS Pathog 13(12): e1006800. doi: 10.1371/journal.ppat.1006800

96. Bouazizi-Ben Messaoud H, Guichard M, Lawton P, Delton I, Azzouz-Maache $S$ (2017). Changes in Lipid and Fatty Acid Composition During Intramacrophagic Transformation of Leishmania donovan Complex Promastigotes into Amastigotes. Lipids 52(5): 433-441. doi: 10.1007/s11745-017-4233-6

97. Gibellini F, Smith TK (2010). The Kennedy pathway--De novo synthesis of phosphatidylethanolamine and phosphatidylcholine. IUBMB Life 62(6): 414-428. doi: 10.1002/iub.337

98. Gibellini F, Hunter WN, Smith TK (2008). Biochemical characterization of the initial steps of the Kennedy pathway in Trypanosoma brucei: the ethanolamine and choline kinases. Biochem J 415(1): 135144. doi: 10.1042/BJ20080435

99. Gibellini F, Hunter WN, Smith TK (2009). The ethanolamine branch of the Kennedy pathway is essential in the bloodstream form of Trypanosoma brucei. Mol Microbiol 73(5): 826-843. doi: 10.1111/j.13652958.2009.06764.x 
100. Farine L, Niemann M, Schneider A, Bütikofer P (2015). Phosphatidylethanolamine and phosphatidylcholine biosynthesis by the Kennedy pathway occurs at different sites in Trypanosoma brucei. Sci Rep 5: 16787. doi: $10.1038 /$ srep 16787

101. Pulido SA, Nguyen VH, Alzate JF, Cedeño DL, Makurath MA, RíosVásquez A, Duque-Benítez SM, Jones MA, Robledo SM, Friesen JA (2017). Insights into the phosphatidylcholine and phosphatidylethanolamine biosynthetic pathways in Leishmania parasites and characterization of a choline kinase from Leishmania infantum. Comp Biochem Physiol B Biochem Mol Biol 213: 45-54. doi: 10.1016/j.cbpb.2017.07.008

102. Bibis SS, Dahlstrom K, Zhu T, Zufferey R (2014). Characterization of Leishmania major phosphatidylethanolamine methyltransferases LmjPEM1 and LmjPEM2 and their inhibition by choline analogs. Mol Biochem Parasitol 196(2): 90-99. doi: 10.1016/j.molbiopara.2014.08.005

103. Moitra S, Basu S, Pawlowic M, Hsu FF, Zhang K (2021). Synthesis of Phosphatidylcholine Is Essential for the Promastigote But Not Amastigote Stage in. Front Cell Infect Microbiol 11: 647870. doi: 10.3389/fcimb.2021.647870

104. Ivens AC, Peacock CS, Worthey EA, Murphy L, Aggarwal G, Berriman M, Sisk E, Rajandream MA, Adlem E, Aert R, Anupama A, Apostolou Z, Attipoe P, Bason N, Bauser C, Beck A, Beverley SM, Bianchettin G, Borzym K, Bothe G, Bruschi CV, Collins M, Cadag E, Ciarloni L, Clayton C, Coulson RM, Cronin A, Cruz AK, Davies RM, De Gaudenzi J, et al. (2005). The genome of the kinetoplastid parasite, Leishmania major. Science 309(5733): 436-442. doi: 10.1126/science. 1112680

105. Sevova ES, Goren MA, Schwartz KJ, Hsu FF, Turk J, Fox BG, Bangs JD (2010). Cell-free synthesis and functional characterization of sphingolipid synthases from parasitic trypanosomatid protozoa. J Biol Chem 285(27): 20580-20587. doi: 10.1074/jbc.M110.127662

106. Merrill AH (2011). Sphingolipid and glycosphingolipid metabolic pathways in the era of sphingolipidomics. Chem Rev 111(10): 63876422. doi: $10.1021 / \mathrm{cr} 2002917$

107. Zhang K, Pompey JM, Hsu FF, Key P, Bandhuvula P, Saba JD, Turk J, Beverley SM (2007). Redirection of sphingolipid metabolism toward de novo synthesis of ethanolamine in Leishmania. EMBO J 26(4): 1094-1104. doi: 10.1038/sj.emboj.7601565

108. Zhang K, Beverley SM (2010). Phospholipid and sphingolipid metabolism in Leishmania. Mol Biochem Parasitol 170(2): 55-64. doi: 10.1016/j.molbiopara.2009.12.004

109. Creek DJ, Anderson J, McConville MJ, Barrett MP (2012). Metabolomic analysis of trypanosomatid protozoa. Mol Biochem Parasitol 181(2): 73-84. doi: 10.1016/j.molbiopara.2011.10.003

110. Berriman $M$, Ghedin E, Hertz-Fowler C, Blandin G, Renauld $H$, Bartholomeu DC, Lennard NJ, Caler E, Hamlin NE, Haas B, Böhme U, Hannick L, Aslett MA, Shallom J, Marcello L, Hou L, Wickstead B, Alsmark UC, Arrowsmith C, Atkin RJ, Barron AJ, Bringaud F, Brooks K, Carrington M, Cherevach I, Chillingworth TJ, Churcher C, Clark LN, Corton $\mathrm{CH}$, Cronin A, et al. (2005). The genome of the African trypanosome Trypanosoma brucei. Science 309(5733): 416-422. doi: 10.1126/science.1112642

111. Acosta H, Burchmore R, Naula C, Gualdrón-López M, QuinteroTroconis E, Cáceres AJ, Michels PAM, Concepción JL, Quiñones W (2019). Proteomic analysis of glycosomes from Trypanosoma cruzi epimastigotes. Mol Biochem Parasitol 229: 62-74. doi: 10.1016/j.molbiopara.2019.02.008

112. Carrero-Lérida J, Pérez-Moreno G, Castillo-Acosta VM, Ruiz-Pérez LM, González-Pacanowska D (2009). Intracellular location of the early steps of the isoprenoid biosynthetic pathway in the trypanosomatids Leishmania major and Trypanosoma brucei. Int J Parasitol 39(3): $307-$ 314. doi: 10.1016/j.ijpara.2008.08.012
113. Saunders EC, Ng WW, Kloehn J, Chambers JM, Ng M, McConville MJ (2014). Induction of a stringent metabolic response in intracellular stages of Leishmania mexicana leads to increased dependence on mitochondrial metabolism. PLoS Pathog 10(1): e1003888. doi: 10.1371/journal.ppat.1003888

114. Yao C, Wilson ME (2016). Dynamics of sterol synthesis during development of Leishmania spp. parasites to their virulent form. Parasit Vectors 9: 200. doi: 10.1186/s13071-016-1470-0

115. Dean S, Sunter JD, Wheeler RJ (2017). TrypTag.org: A Trypanosome Genome-wide Protein Localisation Resource. Trends Parasitol 33(2): 80-82. doi: 10.1016/j.pt.2016.10.009

116. Myler PJ, Fasel N (2006). Leishmania: after the Genome. Caister Academic Press. doi: 10.21775/9781912530304

117. Hettema EH, van Roermund CW, Distel B, van den Berg M, Vilela C, Rodrigues-Pousada C, Wanders RJ, Tabak HF (1996). The ABC transporter proteins Pat1 and Pat2 are required for import of long-chain fatty acids into peroxisomes of Saccharomyces cerevisiae. EMBO J 15(15): 3813-3822. doi: 10.1002/j.1460-2075.1996.tb00755.x

118. Verleur N, Hettema EH, van Roermund CW, Tabak HF, Wanders RJ (1997). Transport of activated fatty acids by the peroxisomal ATPbinding-cassette transporter Pxa2 in a semi-intact yeast cell system. Eur J Biochem 249(3): 657-661. doi: 10.1111/j.1432 1033.1997.00657.x

119. Morita M, Imanaka $T$ (2012). Peroxisomal ABC transporters: structure, function and role in disease. Biochim Biophys Acta 1822(9): 1387-1396. doi: 10.1016/j.bbadis.2012.02.009

120. Colasante C, Alibu VP, Kirchberger S, Tjaden J, Clayton C, Voncken $\mathrm{F}$ (2006). Characterization and developmentally regulated localization of the mitochondrial carrier protein homologue MCP6 from Trypanosoma brucei. Eukaryot Cell 5(8): 1194-1205. doi: 10.1128/EC.00096-06

121. Yernaux C, Fransen M, Brees C, Lorenzen S, Michels PA (2006). Trypanosoma brucei glycosomal $A B C$ transporters: identification and membrane targeting. Mol Membr Biol 23(2): 157-172. doi: 10.1080/09687860500460124

122. Igoillo-Esteve M, Mazet M, Deumer G, Wallemacq P, Michels PA (2011). Glycosomal ABC transporters of Trypanosoma brucei: characterisation of their expression, topology and substrate specificity. Int J Parasitol 41(3-4): 429-438. doi: 10.1016/j.ijpara.2010.11.002

123. McConville MJ, Naderer T (2011). Metabolic pathways required for the intracellular survival of Leishmania. Annu Rev Microbiol 65: 543-561. doi: 10.1146/annurev-micro-090110-102913

124. Ferreira AV, Segatto M, Menezes Z, Macedo AM, Gelape C, de Oliveira Andrade L, Nagajyothi F, Scherer PE, Teixeira MM, Tanowitz HB (2011). Evidence for Trypanosoma cruzi in adipose tissue in human chronic Chagas disease. Microbes Infect 13(12-13): 1002-1005. doi: 10.1016/j.micinf.2011.06.002

125. Richardson JB, Evans B, Pyana PP, Van Reet N, Sistrom M, Büscher $P$, Aksoy $S$, Caccone A (2016). Whole genome sequencing shows sleeping sickness relapse is due to parasite regrowth and not reinfection. Evol Appl 9(2): 381-393. doi: 10.1111/eva.12338

126. Pépin J, Khonde N (1996). Relapses following treatment of earlystage Trypanosoma brucei gambiense sleeping sickness with a combination of pentamidine and suramin. Trans R Soc Trop Med Hyg 90(2): 183-186. doi: 10.1016/s0035-9203(96)90132-7

127. McConville MJ, Ferguson MA (1993). The structure, biosynthesis and function of glycosylated phosphatidylinositols in the parasitic protozoa and higher eukaryotes. Biochem J 294 ( Pt 2): 305-324. doi: 10.1042/bj2940305

128. Morotti ALM, Martins-Teixeira MB, Carvalho I (2019). Protozoan Parasites Glycosylphosphatidylinositol Anchors: Structures, Functions 
and Trends for Drug Discovery. Curr Med Chem 26(23): 4301-4322. doi: 10.2174/0929867324666170727110801

129. Acosta-Serrano A, Vassella $E$, Liniger $M$, Kunz Renggli C, Brun $R$, Roditi I, Englund PT (2001). The surface coat of procyclic Trypanosoma brucei: programmed expression and proteolytic cleavage of procyclin in the tsetse fly. Proc Natl Acad Sci U S A 98(4): 1513-1518. doi: 10.1073/pnas.041611698

130. Ferguson MA, Cross GA (1984). Myristylation of the membrane form of a Trypanosoma brucei variant surface glycoprotein. J Biol Chem 259(5): 3011-3015. doi: 10.1016/s0021-9258(17)43250-9

131. Leppert BJ, Mansfield JM, Paulnock DM (2007). The Soluble Variant Surface Glycoprotein of African Trypanosomes Is Recognized by a Macrophage Scavenger Receptor and Induces IKB $\alpha$ Degradation Independently of TRAF6-Mediated TLR Signaling. J Immunol 179(1): 548556. doi: 10.4049/jimmunol.179.1.548

132. Gazzinelli RT, Denkers EY (2006). Protozoan encounters with Tolllike receptor signalling pathways: implications for host parasitism. Nat Rev Immunol 6(12): 895-906. doi: 10.1038/nri1978

133. Ralton JE, McConville MJ (1998). Delineation of three pathways of glycosylphosphatidylinositol biosynthesis in Leishmania mexicana. Precursors from different pathways are assembled on distinct pools of phosphatidylinositol and undergo fatty acid remodeling. J Biol Chem 273(7): 4245-4257. doi: 10.1074/jbc.273.7.4245

134. Aronson N, Herwaldt BL, Libman M, Pearson R, Lopez-Velez R, Weina $P$, Carvalho E, Ephros M, Jeronimo S, Magill A (2017). Diagnosis and Treatment of Leishmaniasis: Clinical Practice Guidelines by the Infectious Diseases Society of America (IDSA) and the American Society of Tropical Medicine and Hygiene (ASTMH). Am J Trop Med Hyg 96(1): 24-45. doi: 10.4269/ajtmh.16-84256

135. Centers for Disease Control and Prevention. African Trypanosomiasis - Resources for Health Professionals. Available at: https://www.cdc.gov/parasites/sleepingsickness/health professionals index.html\#tx [Acessed 20.03.2021]

136. Ríos-Marco P, Marco C, Gálvez X, Jiménez-López JM, Carrasco MP (2017). Alkylphospholipids: An update on molecular mechanisms and clinical relevance. Biochim Biophys Acta Biomembr 1859(9 Pt B): 1657-1667. doi: 10.1016/j.bbamem.2017.02.016

137. Rakotomanga M, Blanc S, Gaudin K, Chaminade P, Loiseau PM (2007). Miltefosine affects lipid metabolism in Leishmania donovani promastigotes. Antimicrob Agents Chemother 51(4): 1425-1430. doi: 10.1128/AAC.01123-06

138. Paris C, Loiseau PM, Bories C, Bréard J (2004). Miltefosine induces apoptosis-like death in Leishmania donovani promastigotes. Antimicrob Agents Chemother 48(3): 852-859. doi: 10.1128/AAC. 48.3.852-859.2004

139. Luque-Ortega JR, Rivas L (2007). Miltefosine (hexadecylphosphocholine) inhibits cytochrome $c$ oxidase in Leishmania donovani promastigotes. Antimicrob Agents Chemother 51(4): 1327-1332. doi: 10.1128/AAC.01415-06

140. Pinto-Martinez AK, Rodriguez-Durán J, Serrano-Martin X, Hernandez-Rodriguez V, Benaim $G$ (2018). Mechanism of Action of Miltefosine on Leishmania donovani Involves the Impairment of Acidocalcisome Function and the Activation of the SphingosineDependent Plasma Membrane Ca. Antimicrob Agents Chemother 62(1): e01614-17. doi: 10.1128/AAC.01614-17

141. Seifert K (2011). Structures, targets and recent approaches in anti-leishmanial drug discovery and development. Open Med Chem J 5: 31-39. doi: 10.2174/1874104501105010031

142. Sundar S, Chakravarty J, Rai VK, Agrawal N, Singh SP, Chauhan V, Murray HW (2007). Amphotericin B treatment for Indian visceral leishmaniasis: response to 15 daily versus alternate-day infusions. Clin Infect Dis 45(5): 556-561. doi: 10.1086/520665

143. Gangneux JP, Sulahian A, Garin YJ, Farinotti R, Derouin F (1996). Therapy of visceral leishmaniasis due to Leishmania infantum: experimental assessment of efficacy of AmBisome. Antimicrob Agents Chemother 40(5): 1214-1218. doi: 10.1128/AAC.40.5.1214

144. Sundar S, Chakravarty J (2010). Liposomal amphotericin B and leishmaniasis: dose and response. J Glob Infect Dis 2(2): 159-166. doi: 10.4103/0974-777X.62886

145. Stone NR, Bicanic T, Salim R, Hope W (2016). Liposomal Amphotericin B $\left(\right.$ AmBisome $\left.\left.{ }^{\circledR}\right)\right)$ : A Review of the Pharmacokinetics, Pharmacodynamics, Clinical Experience and Future Directions. Drugs 76(4): 485-500. doi: 10.1007/s40265-016-0538-7

146. Biagiotti M, Dominguez S, Yamout N, Zufferey R (2017). Lipidomics and anti-trypanosomatid chemotherapy. Clin Transl Med 6(1): 27. doi: 10.1186/s40169-017-0160-7

147. Berman JD, Gallalee JV, Best JM (1987). Sodium stibogluconate (Pentostam) inhibition of glucose catabolism via the glycolytic pathway, and fatty acid beta-oxidation in Leishmania mexicana amastigotes. Biochem Pharmacol 36(2): 197-201. doi: 10.1016/00062952(87)90689-7

148. t'Kindt R, Scheltema RA, Jankevics A, Brunker K, Rijal S, Dujardin JC, Breitling R, Watson DG, Coombs GH, Decuypere S (2010). Metabolomics to unveil and understand phenotypic diversity between pathogen populations. PLoS Negl Trop Dis 4(11): e904. doi: 10.1371/journal.pntd.0000904

149. Woelke MR, Paulucci NS, Selva A, Garban H, de Lema MG (2017). $\Delta 9$ desaturase from Trypanosoma cruzi: Key enzyme in the parasite metabolism. Cloning and overexpression. Microbiol Res 194: 29-37. doi: 10.1016/j.micres.2016.07.012

150. Jones SM, Urch JE, Kaiser M, Brun R, Harwood JL, Berry C, Gilbert IH (2005). Analogues of thiolactomycin as potential antimalarial agents. J Med Chem 48(19): 5932-5941. doi: 10.1021/jm049067d

151. Waller RF, Keeling PJ, Donald RG, Striepen B, Handman E, LangUnnasch N, Cowman AF, Besra GS, Roos DS, McFadden GI (1998). Nuclear-encoded proteins target to the plastid in Toxoplasma gondii and Plasmodium falciparum. Proc Natl Acad Sci U S A 95(21): 12352 12357. doi: $10.1073 /$ pnas.95.21.12352

152. Jones SM, Urch JE, Brun R, Harwood JL, Berry C, Gilbert IH (2004). Analogues of thiolactomycin as potential anti-malarial and antitrypanosomal agents. Bioorg Med Chem 12(4): 683-692. doi: 10.1016/j.bmc.2003.11.023

153. Morita YS, Paul KS, Englund PT (2000). Specialized fatty acid synthesis in African trypanosomes: myristate for GPI anchors. Science 288(5463): 140-143. doi: 10.1126/science.288.5463.140

154. Phetsuksiri B, Jackson M, Scherman $H$, McNeil M, Besra GS, Baulard AR, Slayden RA, DeBarber AE, Barry CE, Baird MS, Crick DC, Brennan PJ (2003). Unique mechanism of action of the thiourea drug isoxyl on Mycobacterium tuberculosis. J Biol Chem 278(52): 53123-53130. doi: 10.1074/jbc.M311209200

155. Alloatti A, Gupta S, Gualdrón-López M, Igoillo-Esteve M, Nguewa PA, Deumer G, Wallemacq P, Altabe SG, Michels PA, Uttaro AD (2010). Genetic and chemical evaluation of Trypanosoma brucei oleate desaturase as a candidate drug target. PLoS One 5(12): e14239. doi: 10.1371/journal.pone.0014239

156. Stoessel D, Nowell CJ, Jones AJ, Ferrins L, Ellis KM, Riley J, Rahmani R, Read KD, McConville MJ, Avery VM, Baell JB, Creek DJ (2016). Metabolomics and lipidomics reveal perturbation of sphingolipid metabolism by a novel anti-trypanosomal 3-(oxazolo[4,5-b]pyridine-2yl)anilide. Metabolomics 12(7): 126. doi: 10.1007/s11306-016-1062-1 
157. Castro EV, Yoneyama KG, Haapalainen EF, Toledo MS, Takahashi $H K$, Straus AH (2013). Myriocin, a serine palmitoyltransferase inhibitor, blocks cytokinesis in Leishmania (Viannia) braziliensis promastigotes. J Eukaryot Microbiol 60(4): 377-387. doi: 10.1111/jeu.12043

158. Trinconi CT, Miguel DC, Silber AM, Brown C, Mina JGM, Denny PW, Heise N, Uliana SRB (2018). Tamoxifen inhibits the biosynthesis of inositolphosphorylceramide in Leishmania. Int J Parasitol Drugs Drug Resist 8(3): 475-487. doi: 10.1016/j.ijpddr.2018.10.007

159. Andrade-Neto VV, Pereira TM, Canto-Cavalheiro M, TorresSantos EC (2016). Imipramine alters the sterol profile in Leishmania amazonensis and increases its sensitivity to miconazole. Parasit Vectors 9(183. doi: 10.1186/s13071-016-1467-8

160. Garzoni LR, Caldera A, Meirelles MeN, de Castro SL, Docampo R, Meints GA, Oldfield E, Urbina JA (2004). Selective in vitro effects of the farnesyl pyrophosphate synthase inhibitor risedronate on Trypanosoma cruzi. Int J Antimicrob Agents 23(3): 273-285. doi: 10.1016/j.ijantimicag.2003.07.020

161. Leaver DJ, Patkar P, Singha UK, Miller MB, Haubrich BA, Chaudhuri M, Nes WD (2015). Fluorinated Sterols Are Suicide Inhibitors of Ergosterol Biosynthesis and Growth in Trypanosoma brucei. Chem Biol 22(10): 1374-1383. doi: 10.1016/j.chembiol.2015.08.017 